\title{
A Different View on the Etiopathogenesis of Attention-deficit Hyperactivity Disorder from an Inflammation Perspective
}

\author{
Semiha Dursun ${ }^{1}$, Esra Demirci ${ }^{1}$, Eser Kilic ${ }^{2}$, Sevgi Ozmen ${ }^{1}$ \\ Departments of ${ }^{1}$ Child and Adolescent Psychiatry, ${ }^{2}$ Biochemistry, Erciyes University, Kayseri, Turkey
}

Objective: Attention-deficit hyperactivity disorder (ADHD) has a complex etiology and genetic, environmental and biological factors are considered to play a role in the etiology of ADHD by mutually interacting. Recent studies have emphasized that inflammation may be present in the etiology of ADHD. This study aims to investigate the possible role of visfatin, IL-6, IL-1 $\beta$ and TNF- $\alpha$ molecules in the etiology of ADHD.

Methods: The study included 60 patients and 20 healthy controls between the ages of $6-18$. Serum visfatin, IL-6, IL-1 $\beta$ and TNF- $\alpha$ levels were evaluated with enzyme-linked immunosorbent assay (ELISA) kits at a biochemistry laboratory.

Results: The study showed no statistically significant difference between children with ADHD and healthy controls in terms of visfatin, IL-6, IL-1 $\beta$ and TNF- $\alpha$ levels. When ADHD subgroups (combined and predominantly inattentive types) and the control group were compared in terms of visfatin, IL-6, IL-1 $\beta$ and TNF- $\alpha$ levels, no statistically significant difference was recorded.

Conclusion: Data on the relationship between ADHD and IL-6, IL-1 $\beta$ and TNF- $\alpha$ in this study are in compliance with the literature. However, no study was found on visfatin in ADHD. This study is the first one evaluating the ADHD-Visfatin relationship.

KEY WORDS: Attention deficit disorder with hyperactivity; Interleukin-1 beta; Interleukin-6; Inflammation; Tumor necrosis factor-alpha; Visfatin.

\section{INTRODUCTION}

By mutually interacting, several genetic, environmental and biological factors are considered to play a role in the etiology of attention-deficit hyperactivity disorder (ADHD) which has a complex etiology $[1,2]$. Recent studies have emphasized that inflammation may also have a role in the etiology of ADHD. Inflammation has been asserted to have an effect on the development of neuropsychiatric diseases such as ADHD by causing damage at the blood brain barrier through glial activation, neuronal damage, oxidative stress and neurotrophic factors [3]. Detection of increased risk for ADHD in patients with inflammatory

Received: May 25, 2020 / Revised: July 6, 2020

Accepted: September 30, 2020

Address for correspondence: Sevgi Ozmen

Department of Child and Adolescent Psychiatry, Erciyes

University, Köşk Mahallesi, Prof. Dr. Turhan Feyzioğlu Caddesi,

No:42, Melikgazi, Kayseri 38039, Turkey

E-mail: drsevgiozmen@gmail.com

ORCID: https://orcid.org/0000-0002-7545-2824 and autoimmune diseases, inflammation-associated genes, and studies on markers associated with inflammation support the role of inflammatory mechanisms in the occurrence of $\mathrm{ADHD}$ [3].

When the studies on the relationship between ADHD and inflammation were evaluated, inflammatory cytokines are considered to affect tryptophan and dopamine pathways that play an important role in the etiology of ADHD [4]. It is known that IL- $1 \beta$ is a molecule expressed in the brain, regulates neuronal growth during the prenatal period and plays a role in the differentiation of mesencephalic progenitor cells into dopaminergic neurons [5]. IL-1 $\beta$ also increases norepinephrine and serotonin turnover in the hypothalamus and prefrontal cortex [6]. Proinflammatory cytokines such as TNF- $\alpha$ and IL- 6 cause the activation of glutamate receptors and decrease the effects of glycine and gamma-aminobutyric acid. While IL-6 and TNF- $\alpha$ at normal levels protect neurons and glial cells against toxicity caused by glutamate, TNF- $\alpha$ and IL-6

@) This is an Open-Access article distributed under the terms of the Creative Commons Attribution Non-Commercial License (http://creativecommons.org/licenses/by-nc/4.0) which permits unrestricted non-commercial use, distribution, and reproduction in any medium, provided the original work is properly cited. 
levels increase in the case of hypoxia and cause brain damage [7]. It has been reported that increased IL-6 levels may change neural pathways of the developing brain and affect attention and memory with its effect on neurogenesis and synaptic plasticity in the prefrontal cortex and hippocampus $[8,9]$.

Visfatin is a molecule that increases the manufacture of IL-6, IL-1 $\beta$ and TNF- $\alpha$ and therefore, it is accepted as a cytokine [10]. Visfatin is an inflammatory marker and also an adipokine as it is synthesized from adipose tissue. There are adipocyte receptors in many areas of the central nervous system and these receptors have been revealed to affect neuroplastic processes [11]. As visfatin is also an adipokine, it may affect adipokine receptors in the central nervous system and may be effective in neuroplastic processes. At the same time, visfatin can indirectly trigger inflammation with its effects in the production of IL-6, IL-1 $\beta$ and TNF- $\alpha$, and may trigger ADHD pathogenesis by affecting the inflammatory pathways, suggested to be effective in the etiology of ADHD via IL-6, IL-1 $\beta$ and TNF- $\alpha$.

Many studies have examined the relationship between IL-6, IL-1 $\beta$ and TNF- $\alpha$ and ADHD in the literature. In a study, IL-6 serum levels were found to be higher in individuals with ADHD [12]. In another study, IL-6 plasma level was significantly higher in the ADHD group, while TNF- $\alpha$ level was lower [13]. ADHD risk increases in individuals carrying 4 repeating alleles of IL-1Ra and the risk decreases in individuals carrying 2 repeating alleles in a genetic study on IL-1 [5]. A different study has shown that serum IL-1 $\beta$ level was higher in the ADHD group than in healthy controls, while serum TNF- $\alpha$ level was lower in the ADHD group in the same study [14]. An ADHD model was created and the level of some cytokines in the brain was examined in a study in rats. This study shows that TNF- $\alpha$ decreased in the prefrontal cortex, cortex, hippocampus and striatum [15]. Study data indicate that IL-6, IL-1 $\beta$ and TNF- $\alpha$ may be effective in the pathogenesis of ADHD. No study investigating the relationship between visfatin and ADHD has been found. However, due to the effect of visfatin on IL-6, IL-1 $\beta$ and TNF- $\alpha$, it may be effective in $\mathrm{ADHD}$ pathogenesis by indirectly triggering peripheral and central inflammation. Although the relationship between visfatin and ADHD has not been studied in the literature, there are studies investigating the relationship between visfatin and other psychiatric diseases. In a study with individuals with autism who have a neuro- developmental disorder such as ADHD, serum visfatin level has been shown to be higher in individuals with autism than in healthy controls [16]. Other studies are seen to examine the relationship between eating disorders and visfatin. In one study, a positive relationship was found between binge eating and serum visfatin levels and these factors could be predictors of each other [17]. In another study, serum visfatin level was found to be lower in anorexia nervosa compared to healthy controls [18]. Additional studies show that common etiological factors play a role between eating disorders and ADHD. Impairment in dopamine and reward pathways and executive functions such as working memory, attention and emotion control may exist in both ADHD and eating disorders [19]. Some symptoms seen in bulimia nervosa, one of the most common eating disorders accompanying ADHD, are associated with impulsivity $[20,21]$. The possible role of visfatin is valid in the complex etiology of ADHD when considering the similar etiological factors and common clinical patterns of eating disorders and ADHD.

Based on data found in the literature, this study examines the effects of IL-6, IL-1 $\beta$, TNF- $\alpha$ and visfatin on ADHD etiology. Data obtained from this study can be supported by data obtained from studies previously examining the relationship between ADHD and IL-6, IL-1 $\beta$ and TNF- $\alpha$. In addition, there is no study investigating the relationship between ADHD and visfatin in the literature. The effects of visfatin, which is known to be closely related to IL-6, IL-1 $\beta$ and TNF- $\alpha$, in ADHD pathogenesis can be examined and new data can be added to the literature in terms of ADHD pathogenesis based on this study.

\section{METHODS}

\section{Participants}

The study was authorized by the Research Ethics Committee of Erciyes University Faculty of Medicine with decision number of 2018/296 on 23.05.2018. A total of 60 patients (30 with a presentation of ADHD-predominantly inattentive type and 30 with a presentation of ADHD-combined type) and 20 healthy children between the ages of 6-18 who were admitted to the Child and Adolescent Psychiatry Outpatient Clinic of Erciyes University Faculty of Medicine during the period of 20182019 were incorporated into the study. These patients were diagnosed with ADHD according to the diagnostic 
criteria of the Diagnostic and Statistical Manual of Mental Disorders 5th edition (DSM-V). The children and their families invited to participate were informed about the study by the researcher and their written consent was obtained.

The Schedule for Affective Disorders and Schizophrenia for School-Aged Children-Present and Lifetime Version (K-SADS-PL) was used to interview all the children in the study. The children included in the study were newly diagnosed or had not been taking medication (stimulant and non-stimulant) for at least the past 6 months. Children who had a comorbid psychiatric disease (apart from oppositional defiant disorder, conduct disorder, enuresis and encopresis), mental retardation, any known additional chronic disease, an acute or chronic infection, anti-inflammatory treatment use in the last month, chronic medication use and whose weight was below the 5th percentile or above the 95th percentile were excluded from the study.

The control group was matched with the patient group in terms of age and sex and 20 volunteer children and adolescents between the ages of 6 and 18 along with their parents, who had no mental retardation, no known additional psychiatric or chronic disease, no acute or chronic infection, no anti-inflammatory treatment use in the past month, no chronic medication use and whose weight was between the 5th and 95th percentiles were incorporated into the control group of the study.

\section{Clinical Assessment}

Parents of the children and adolescents included in the study were asked to complete a sociodemographic data form, Atilla Turgay DSM-IV Based Screening and Rating Scale for Children and Adolescents with Behavior Disorders (T-DSMIV-S), and Conners' Parent Rating Scale (CPRS) regarding their children. At the same time, teachers were asked to complete the T-DSMIV-S and CTRS. K-SADS-PL was used to interview the children and adolescents by the researcher in order to evaluate whether the children included in the study had any additional psychiatric diseases.

\section{Sociodemographic Information Form}

The sociodemographic characteristics of the children and adolescents participating in the study were evaluated using a form prepared by the researcher. In this form, chil- dren's age, sex, academic achievement, medical history, weight, height and parents' age and educational status were evaluated with closed-ended questions.

\section{Schedule for Affective Disorders and Schizophrenia for School-Aged Children-Present and Lifetime Version (K-SADS-PL)}

$\mathrm{K}-\mathrm{SADS}-\mathrm{PL}$ is a semi-structured interview form. It was adapted to Turkish by Gökler et al. [22]. The validity and reliability study was carried out in 2004. Using the K-SADS-PL, an evaluation can be made in terms of 20 different psychiatric diagnoses according to DSM-III-R and DSM-IV diagnostic criteria in children and adolescents aged 6-18 [22]

\section{Atilla Turgay Screening and Evaluation Scale Based on DSM-IV for Behavioral Disorders in Children and Adolescents (T-DSMIV-S)}

T-DSMIV-S was prepared by Atilla Turgay considering DSM-IV diagnostic criteria. With this scale, screening and evaluation of ADHD, oppositional defiant disorder and conduct disorder are performed. The scale consists of 41 questions. Nine questions are related to attention deficit, nine questions are related to hyperactivity, eight questions are concerning oppositional defiant disorder, and 15 questions are related to symptoms of conduct disorder. The answer to each question can be given as (0) "none", (1) “a little”, (2) "more” and (3) "a lot" [23].

\section{Conners' Parent Rating Scale (CPRS)}

CPRS is a 48-item assessment scale that identifies symptoms of attention deficit, hyperactivity, behavioral problems, and anxiety disorder. This scale was completed by the parents. The questions were created according to a 4-point Likert-type scale and the options are (0) "never", (1) “rarely”, (2) “often”, (3) “always” [23].

\section{Conners' Teacher Rating Scale (CTRS)}

CTRS is a scale developed for teachers to evaluate students' classroom behavior. The scale consists of 28 items. The questions in this scale are formed according to the 4-point Likert-type scale and the responses are (0) "never", (1) “rarely”, (2) “often”, (3) “always” [23].

\section{Biochemical Measurements}

A blood sample of $5-10 \mathrm{ml}$ was taken from the patients 
and control groups in anti-coagulant-free biochemistry tubes for measurement of visfatin, IL- 6 , IL-1 $\beta$ and TNF- $\alpha$ levels between 8-9 AM. The collected blood samples were centrifuged for 15 minutes at 4,000 rpm. After centrifugation, the denser elements in the blood fall with the help of coagulants in the tube, and a clot forms at the bottom of the tube. The liquid part (serum) remaining on the clot was put into cryotubes and stored at $-80^{\circ} \mathrm{C}$ before analysis. Serum visfatin, TNF- $\alpha$, IL-1 $\beta$, and IL-6 levels were evaluated with Enzyme-linked immunosorbent assay (Bioassay Technology Laboratory Human ELISA Kit) kits at the biochemistry laboratory. The sensitivity values for visfatin, IL-6, IL-1 $\beta$ and TNF- $\alpha$ were $0.23 \mathrm{ng} / \mathrm{ml}, 1.52$ $\mathrm{ng} / \mathrm{L}, 10.07 \mathrm{pg} / \mathrm{L}$, and $1.03 \mathrm{ng} / \mathrm{L}$, respectively.

\section{Statistical Analysis}

Data were analyzed using the Statistical Package Software Program for Social Sciences (SPSS for Windows, 20.0; IBM Co., Armonk, NY, USA). Non-parametric tests were used for all variables. Mann-Whitney $U$ Test and chi-square test were used for differences between the two groups. Kruskal-Wallis test was used to compare biochemical parameters of the patient subtypes and healthy controls and Spearman correlation test was used to evaluate associations for variables. Data were given as median, minimum, maximum, percentile and numbers. The threshold for statistical significance level for all the analyses was accepted as $p<0.05$.

\section{RESULTS}

The patient group participating in this study consisted of 60 children and adolescents (30 with presentation of ADHD-predominantly inattentive type and 30 with a presentation of ADHD-combined type) admitted to the Child
Psychiatry Outpatient Clinic of Erciyes University Faculty of Medicine and diagnosed with ADHD according to DSM-V criteria and 20 healthy children and adolescents who were not diagnosed with a psychiatric disease. The mean age of the children in the group with ADHD was $9.39 \pm 2.8$ and the median value was $8.0(6.0-17.0)$, the mean age of the children in the control group was $9.39 \pm$ 2.8 and the median value was $9.0(6.0-15.0)$. When ADHD and control groups were compared in terms of age, no significant difference was found between the groups $(p>0.05)$ (Table 1).

Mean height, weight and body mass index in the group with ADHD were $135.3 \pm 18 \mathrm{~cm}, 33.01 \pm 11.31 \mathrm{~kg}$, and body mass index (BMI) $17.2 \pm 2.57$, respectively. Mean height, weight and body mass index in the control group were $134.9 \pm 15.6 \mathrm{~cm}, 33.5 \pm 12.08 \mathrm{~kg}$, and BMI $17.7 \pm$ 2.68 , respectively. When ADHD and the control groups were compared in terms of height, weight and body mass index, there was no statistically significant difference $(p>$ 0.05) (Table 1).

In the evaluation of the patient and control groups in terms of sex, there were 9 females and 51 male participants in the patient group and 4 females and 16 male participants in the control group. No difference was recorded between the patient and control groups in terms of $\operatorname{sex}(p=$ 0.727) (Table 1).

In the comparison of scale scores, T-DSMIV-S teacher and family hyperactivity and Conners' Parent and Teacher Scale scores were higher in the presentation of ADHD-combined type compared to the scores in the presentation of ADHD-predominantly inattentive type ( $p<$ 0.05). Although the T-DSMIV-S teacher and family inattention scores were higher in the presentation of the combined type compared to the presentation of the predominantly inattentive type, the difference between these

Table 1. Characteristics of patients and healthy controls

\begin{tabular}{lccc}
\hline \multicolumn{1}{c}{ Characteristic } & ADHD group $(\mathrm{n}=60)$ & Control group $(\mathrm{n}=20)$ & Comparison \\
\hline Age $(\mathrm{yr})$ & $8.0(6.0-17.0)$ & $9.0(6.0-15.0)$ & $\mathrm{Z}=0.309^{*}, p=0.758$ \\
Sex & $9(15)$ & $4(20)$ & $\chi^{2}=0.276^{* *}, p=0.727$ \\
$\quad$ Female & $51(85)$ & $16(80)$ & \\
Male & $27.7(17.9-73.5)$ & $33.0(19.5-62.0)$ & $\mathrm{Z}=0.233^{*}, p=0.815$ \\
Weight $(\mathrm{kg})$ & $131.6(110.0-177.9)$ & $135.0(116.8-178.0)$ & $\mathrm{Z}=0.111^{*}, p=0.912$ \\
Height $(\mathrm{cm})$ & $16.7(13.4-27.4)$ & $17.2(14.2-23.6)$ & $\mathrm{Z}=0.828^{*}, p=0.408$ \\
Body mass index $\left(\mathrm{kg} / \mathrm{m}^{2}\right)$ &
\end{tabular}

Values are presented as median ( $\min -\max$ ) or number (\%). ADHD, attention-deficit hyperactivity disorder.

*Mann -Whitney $U$ test. ${ }^{* *}$ Chi-square test. 
Table 2. Comparison of ADHD subtypes with Atilla Turgay and Conners' scale scores

\begin{tabular}{lccl}
\hline \multicolumn{1}{c}{ Variable } & Combined type & Predominantly inattentive type & \multicolumn{1}{c}{ Comparison* $^{*}$} \\
\hline Atilla Turgay inattention score (family) & $15.5(8-24)$ & $14(7-24)$ & $\mathrm{Z}=0.489, p=0.624$ \\
Atilla Turgay hyperactivity score (family) & $15(4-27)$ & $7(0-19)$ & $\mathrm{Z}=4.017, p<0.001^{\dagger}$ \\
Atilla Turgay inattention score (teacher) & $17(8-27)$ & $16(8-25)$ & $\mathrm{Z}=0.764, p=0.445$ \\
Atilla Turgay hyperactivity score (teacher) & $16(8-25)$ & $5(0-10)$ & $\mathrm{Z}=6.558, p<0.001^{\dagger}$ \\
Conners' parent form & $43.5(16-94)$ & $34(14-74)$ & $\mathrm{Z}=2.936, p=0.003^{\dagger}$ \\
Conners' teacher form & $43(18-59)$ & $25.5(12-42)$ & $\mathrm{Z}=4.949, p<0.001^{\dagger}$ \\
\hline
\end{tabular}

Values are presented as median (min-max). ADHD, attention-deficit hyperactivity disorder.

*Mann-Whitney $U$ test. ${ }^{\dagger} p$ value is significant $<0.05$.

Table 3. Comparison of visfatin, IL-1 $\beta$, IL- 6 and TNF- $\alpha$ levels of ADHD and control group

\begin{tabular}{lccc}
\hline \multicolumn{1}{c}{ Variable } & ADHD group & Control group & Comparison* $^{*}$ \\
\hline Visfatin $(\mathrm{ng} / \mathrm{ml})$ & $9.59(3.3-67)$ & $9.47(1-67)$ & $\mathrm{Z}=0.156, p=0.876$ \\
IL-1 $\beta(\mathrm{pg} / \mathrm{L})$ & $374.1(62.5-4,187.5)$ & $354.1(62.5-4,001.9)$ & $\mathrm{Z}=0.056, p=0.956$ \\
IL-6 $(\mathrm{ng} / \mathrm{L})$ & $33.5(5-335)$ & $42.1(5-335)$ & $\mathrm{Z}=0.224, p=0.823$ \\
TNF- $\alpha(\mathrm{ng} / \mathrm{L})$ & $66.0(7.7-502.5)$ & $76.3(8.7-502.5)$ & $\mathrm{Z}=0.222, p=0.824$ \\
\hline
\end{tabular}

Values are presented as median $(\mathrm{min}-\mathrm{max})$. ADHD, attention-deficit hyperactivity disorder.

*Mann - Whitney $U$ test, Effect size of visfatin: 0.060, IL-1ß: 0.128, IL-6: 0.215, TNF- $\alpha$ : 0.100 .

Table 4. Comparison of ADHD Subtypes with the control group in terms of visfatin, IL-1 $1 \beta$, IL- 6 and TNF- $\alpha$ levels

\begin{tabular}{lcccc}
\hline \multicolumn{1}{c}{ Variable } & Combined type & Predominantly inattentive type & Control group & Comparison* \\
\hline Visfatin $(\mathrm{ng} / \mathrm{ml})$ & $9.59(3.3-67)$ & $9.6(4-58.2)$ & $9.47(1-67)$ & $\mathrm{Z}=0.135, p=0.935$ \\
IL-1 $\beta(\mathrm{pg} / \mathrm{L})$ & $400.1(62.5-4,187.5)$ & $357.7(62.5-2,267.3)$ & $354.1(62.5-4,001.9)$ & $\mathrm{Z}=0.031, p=0.985$ \\
IL-6 $(\mathrm{ng} / \mathrm{L})$ & $34.04(5-335)$ & $30.9(5-335)$ & $42.1(5-335)$ & $\mathrm{Z}=0.093, p=0.955$ \\
TNF- $\alpha(\mathrm{ng} / \mathrm{L})$ & $63.5(7.7-502.5)$ & $73.8(11.3-422.1)$ & $76.3(8.7-502.5)$ & $\mathrm{Z}=0.139, p=0.933$ \\
\hline
\end{tabular}

Values are presented as median ( $\min -\max )$.

ADHD, attention-deficit hyperactivity disorder.

*Kruskal-Wallis test.

scale scores was not statistically significant $(p>0.05)$ (Table 2).

Mean visfatin, IL-6, IL-1 $\beta$ and TNF- $\alpha$ in the group with ADHD were $16.2 \pm 15.8,74.7 \pm 95.9,681.4 \pm 797.1$, $121.7 \pm 133.6$, respectively and mean of these values in control group were $17.4 \pm 19.5,96.6 \pm 118.3,791.2 \pm$ $1,015.7,135.3 \pm 143.1$, respectively. When the patient and control groups were compared in terms of visfatin, IL-6, IL-1 $\beta$ and TNF- $\alpha$ levels, no significant difference was found between the groups ( $p>0.05$ ) (Table 3).

No statistically significant difference was found between the presentation of combined and predominantly inattentive types of ADHD and the control group in terms of visfatin, IL-6, IL-1 $\beta$, and TNF- $\alpha$ levels (Table 4).

When the correlation of the data was evaluated, no correlation was found between the scores of T-DSMIV-S, Conners' Parent Rating scale scores, Conners' Teacher Rating scale scores, weight and visfatin, IL-6, IL-1 $\beta$,
TNF- $\alpha(p>0.05)$ (Table 5). A positive correlation was found between visfatin and IL-6, IL-1 $\beta$, TNF- $\alpha$ ( $p<$ 0.001). A negative correlation was found between body mass index and IL-6, IL-1 $\beta$, TNF- $\alpha(p<0.05)$. There was no significant correlation between body mass index and visfatin $(p>0.05)$ (Table 5).

\section{DISCUSSION}

IL-1 is an important cytokine investigated with ADHD in which etiological evidence is increasing. While a genetic study reported that some of the IL-1Ra gene alleles affected the risk of ADHD, another study found that IL-1Ra gene alleles had no effect on ADHD risk [5,24]. A study evaluating the serum level of IL-1 $\beta$ found the level was higher in the ADHD group than healthy controls [14]. In contrast, in another study investigating the relationship between oxidative stress and ADHD, plasma IL-1 $\beta$ levels 
Table 5. Correlation table between data

\begin{tabular}{|c|c|c|c|c|}
\hline Variable & Visfatin* & IL-1 $\beta^{*}$ & IL-6* & TNF- $\alpha^{*}$ \\
\hline \multicolumn{5}{|l|}{ Visfatin } \\
\hline r & 1 & 0.954 & 0.918 & 0.937 \\
\hline$p$ & - & $<0.001$ & $<0.001$ & $<0.001$ \\
\hline \multicolumn{5}{|l|}{ IL-1 $\beta$} \\
\hline r & 0.954 & 1 & 0.911 & 0.914 \\
\hline$p$ & $<0.001$ & - & $<0.001$ & $<0.001$ \\
\hline \multicolumn{5}{|l|}{ IL-6 } \\
\hline$r$ & 0.918 & 0.911 & 1 & 0.923 \\
\hline$p$ & $<0.001$ & $<0.001$ & - & $<0.001$ \\
\hline \multicolumn{5}{|l|}{ TNF- $\alpha$} \\
\hline$r$ & 0.937 & 0.914 & 0.923 & 1 \\
\hline$p$ & $<0.001$ & $<0.001$ & $<0.001$ & - \\
\hline \multicolumn{5}{|l|}{ Weight } \\
\hline r & -0.098 & -0.124 & -0.172 & -0.121 \\
\hline$p$ & 0.386 & 0.271 & 0.126 & 0.283 \\
\hline \multicolumn{5}{|l|}{ Body mass index } \\
\hline r & -0.172 & -0.222 & -0.313 & -0.222 \\
\hline$p$ & 0.127 & 0.047 & 0.005 & 0.048 \\
\hline \multicolumn{5}{|c|}{ Atilla Turgay inattention score (family) } \\
\hline r & -0.212 & -0.216 & -0.160 & -0.179 \\
\hline$p$ & 0.103 & 0.098 & 0.223 & 0.172 \\
\hline \multicolumn{5}{|c|}{ Atilla Turgay hyperactivity score (family) } \\
\hline r & -0.099 & -0.073 & -0.077 & -0.073 \\
\hline$p$ & 0.453 & 0.579 & 0.559 & 0.580 \\
\hline \multicolumn{5}{|c|}{ Atilla Turgay inattention score (teacher) } \\
\hline r & 0.030 & 0.102 & 0.021 & 0.085 \\
\hline$p$ & 0.822 & 0.438 & 0.876 & 0.521 \\
\hline \multicolumn{5}{|c|}{ Atilla Turgay hyperactivity score (teacher) } \\
\hline r & -0.068 & -0.004 & -0.065 & -0.046 \\
\hline$p$ & 0.604 & 0.977 & 0.620 & 0.729 \\
\hline \multicolumn{5}{|c|}{ Conners parent form scale } \\
\hline$r$ & 0.017 & 0.012 & 0.111 & 0.009 \\
\hline$p$ & 0.895 & 0.927 & 0.400 & 0.945 \\
\hline \multicolumn{5}{|c|}{ Conners teacher form scale } \\
\hline$r$ & -0.142 & -0.060 & -0.129 & -0.093 \\
\hline$p$ & 0.278 & 0.647 & 0.326 & 0.481 \\
\hline
\end{tabular}

-, not available.

*Spearman's rho test.

did not differ between ADHD and controls [25]. A different study conducted by Oades et al. [7] showed that the IL-1 $\beta$ level was lower than the control group, but this difference was not statistically significant. Similarly, in this study, no statistically significant difference was found between ADHD and the control group in terms of IL- $1 \beta$ serum levels. In the study carried out by Oades et al. [7], the ADHD group consisted of 21 children who were diagnosed as a combined subtype; however, this study sample was divided into 30 inattentive dominant subtypes and 30 combined subtypes. In addition, the patient groups included in the study were divided into two groups as treat- ment and non-treatment and a comparison was made between these two groups. Although IL-1 $\beta$ level was higher in the treated group than the untreated group, no statistical difference was found in the comparison between the groups [7]. However, in this study, the children were newly diagnosed and had not been taking medication.

In some of the studies in which the relationship between IL-6 serum level and ADHD was investigated, IL-6 level was higher in the ADHD group [12,26]. In another study in which oxidative stress and immune system changes were analyzed in ADHD, IL-6 levels in ADHD group were no different from those in the control group 
[25]. Similarly, no difference was found between ADHD group and the healthy controls in terms of IL- 6 levels in this study. Moreover, no difference was found between ADHD subtypes (in the presentation of combined and predominantly inattentive types) and the control group in terms of IL-6 levels in this study. In a study on adults with ADHD, IL-6 levels were compared among predominantly inattentive type, combined type and control group and no difference was found among the groups, which is similar to this study [27].

A study with rats in which the relationship between TNF- $\alpha$ and ADHD was evaluated TNF- $\alpha$ decreased in the prefrontal cortex, hippocampus and striatum [15]. When the results of two separate studies were examined, the TNF- $\alpha$ level was lower in the ADHD group $[13,14]$. Contrary to these data, studies were found to show that TNF- $\alpha$ level did not show a significant difference in ADHD. In the study by Verlaet et al. [25], no difference was found between ADHD and control group in terms of TNF levels. In a different study on adults, no difference was found between the patients with ADHD and healthy controls in terms of TNF- $\alpha$ levels [27]. The results of that study are consistent with those of the current study, and similarly, TNF- $\alpha$ levels did not differ between ADHD group and the control group in this study. TNF- $\alpha$ did not differ between different presentations of ADHD (predominantly inattentive type and ADHD-combined type) and the control groups in this study. These data were consistent with the results of the study by Corominas-Roso et al. [27]. Similar to this study, TNF- $\alpha$ levels in the combined type and predominantly inattentive type ADHD were not different from those in the control group in that study [27]. In compliance with all those data, no statistical difference was found between ADHD group and control group in terms of TNF- $\alpha$ level in the study by Oades et al.[7].

When all the study results were evaluated, different results were obtained in terms of cytokine levels. Although there are studies showing that cytokines may be related to ADHD, there are many studies similar to the current study finding that cytokines did not differ significantly in the group with ADHD. The number of people participating in the study, medication use, age of the participants, and the groups compared in the study are thought to affect the results of the study. In addition, in most of the studies, only the peripheral level of cytokines was examined. However, most cytokines can impact ADHD pathogenesis by affecting the central nervous system. Further studies measuring the levels of cytokines in the central nervous system are purported to obtain more meaningful data. Also comparing the cytokine levels in the periphery and those in the central nervous system are important. Peripheral and central inflammation is reported to potentiate each other [4]; however, this should be supported with more concrete data. In addition, knowing the peripheral levels of cytokines such as IL-6, IL-1 $\beta$, TNF- $\alpha$ as well as their levels in the central nervous system may be more significant in terms of determining the relationship of these cytokines with ADHD.

This study showed no statistically significant difference between the groups in terms of visfatin serum levels. When the literature was examined, no study investigating the relationship between ADHD and visfatin was found. In a study investigating the relationship between autism and visfatin, visfatin serum levels were higher in the group with autism than the healthy controls [16]. There is a need for new and more comprehensive studies evaluating visfatin in both autism and ADHD. In addition to being an inflammatory marker of visfatin, it is also an adipokine and adipocyte receptors are in many areas in the central nervous system. Adipocyte receptors have been shown to be effective in neuroplastic processes [11]. As visfatin is an adipokine, there are studies investigating the relationship between visfatin and eating disorders. In a study conducted with patients with anorexia nervosa, visfatin plasma levels were higher than in healthy controls [28]. In one study, visfatin levels were lower in anorexia nervosa, in a different study, there was no difference in terms of visfatin levels between anorexia nervosa and bulimia nervosa and healthy controls $[18,29]$. The differences reported in visfatin levels in eating disorders may be the result of the mutual influence of many factors, including patient age, body fat distribution and metabolic activity of fat cells. In the literature, it is seen that most studies investigating the relationship between visfatin and psychiatric disease are based on the relationship between visfatin and inflammation and being an adipokine. Further studies should be carried out in the future on which pathways visfatin affect in the central nervous system. If it can be clearly demonstrated which pathways visfatin affects in the central nervous system, more meaningful data on the role of visfatin in ADHD and other psychiatric diseases can be obtained. 
In our study, no relation was found between visfatin, IL-6, IL-1 $\beta$ and TNF- $\alpha$ levels, the T-DSMIV-S, the Conners' Teacher and the Conners' Parent Rating Scale scores. There are no studies in the literature investigating the relationship between ADHD symptoms and visfatin. In a study examining the relationship between IL-6 and ADHD, no relation was found between Conners' Parent Rating Scale score and IL-6 level as in this study [12]. Similarly, in another study, no relation was found between TNF- $\alpha$ and IL-6 and Conners' ADHD Rating Scale scores [27]. Another study found no correlation between IL-6, IL-1 $\beta$ and TNF- $\alpha$ levels and carelessness and hyperactivity scores in line with the results of these studies [30]. When the results of the study are evaluated, there is no relationship between ADHD symptoms (hyperactivity and carelessness) and cytokines such as IL-6, IL-1 $\beta$ and TNF- $\alpha$ in this and other studies. The fact that similar results were obtained in all studies and in this study suggests that these cytokines may not be associated with ADHD symptoms. However, different and meaningful data can be obtained through larger sample studies.

This study showed a positive correlation between visfatin and IL-6, IL-1 $\beta$, TNF- $\alpha$. Visfatin is known to have an effect on IL-6, IL-1 $\beta$ and TNF production and data obtained in this study confirms this information. Another study shows a positive correlation between visfatin and TNF- $\alpha$, supporting the data obtained in this study [16]. In another study, a positive correlation was found between visfatin and IL-6 [31].

In this study, no correlation was found between body mass index and visfatin. Contradictory results were seen when this subject is examined. One study found no correlation between visfatin and body mass index, as in this study [16]. In another study, no correlation was found between body mass index and visfatin in the group with anorexia nervosa. In that same study, there was a negative correlation between body mass index and visfatin in the obese group, and a positive correlation between body mass index and visfatin in the group with normal body mass index [18]. In this study, a negative correlation was found between IL- 6 , IL- $1 \beta$ and TNF- $\alpha$ and body mass index. One study in the literature found a positive correlation between body mass index and TNF- $\alpha$ and IL-6 [32] In another study, no significant correlation was found between body mass index and TNF- $\alpha$ [16]. These data should be supported with other studies to evaluate wheth- er the relationship found in this study was a random relationship.

Although there have been studies on the ADHD population associated with IL-6, IL-1 $\beta$ and TNF- $\alpha$, this is the first study to investigate the relationship between visfatin and ADHD, which is known to be associated with cytokines such as IL-6, IL-1 $\beta$ and TNF- $\alpha$. More studies are needed on the relationship of these molecules to ADHD. Limitations of the study include a limited number of children and adolescents with ADHD participating in the study, the number of children and adolescents in the control group was lower than the patient group, the hyperactivity dominant type of ADHD was not included in the study and the levels of visfatin, IL-6, IL-1 $\beta$ and TNF- $\alpha$ in the central nervous system were not examined. Data obtained from this study can be expanded with larger sample studies in the future. Also, in order to reach more meaningful data, future studies can include which pathways visfatin, IL-6, IL-1 $\beta$, TNF- $\alpha$ and other inflammatory markers affect in the brain. Clearly identifying which visfatin, IL-6, IL-1 $\beta$, TNF- $\alpha$ and other inflammatory markers affect the central nervous system, more meaningful data about the roles of these substances in ADHD and other psychiatric diseases can be obtained.

\section{Conflicts of Interest}

No potential conflict of interest relevant to this article was reported.

\section{Author Contributions}

Conceptualization: Semiha Dursun, Sevgi Ozmen, Esra Demirci. Data cquisition: Semiha Dursun, Sevgi Ozmen, Esra Demirci. Biochemical analysis: Eser Kilic. Supervision: Sevgi Ozmen, Esra Demirci. Writing - original draft: Semiha Dursun. Writing - review \& editing: Semiha Dursun, Sevgi Ozmen.

\section{ORCID}

Semiha Dursun https://orcid.org/0000-0001-8368-4775

Esra Demirci https://orcid.org/0000-0002-8424-4947

Eser Kilic https://orcid.org/0000-0002-0459-8228

Sevgi Ozmen https://orcid.org/0000-0002-7545-2824

\section{REFERENCES}

1. Faraone SV, Perlis RH, Doyle AE, Smoller JW, Goralnick JJ, Holmgren MA, et al. Molecular genetics of attention-defi- 
cit/hyperactivity disorder. Biol Psychiatry 2005;57:1313-1323.

2. Percinel I, Yazici KU, Ustundag B. Iron deficiency in the pathophysiology of attention deficit hyperactivity disorder. Current Approaches to Psychiatry 2015;7:41-55.

3. Leffa DT, Torres ILS, Rohde LA. A review on the role of inflammation in attention-deficit/hyperactivity disorder. Neuroimmunomodulation 2018;25:328-333.

4. Anand D, Colpo GD, Zeni G, Zeni CP, Teixeira AL. Attentiondeficit/hyperactivity disorder and inflammation: what does current knowledge tell us? A systematic review. Front Psychiatry 2017;8:228.

5. Segman RH, Meltzer A, Gross-Tsur V, Kosov A, Frisch A, Inbar $\mathrm{E}$, et al. Preferential transmission of interleukin-1 receptor antagonist alleles in attention deficit hyperactivity disorder. Mol Psychiatry 2002;7:72-74.

6. Zalcman S, Green-Johnson JM, Murray L, Nance DM, Dyck D, Anisman $\mathrm{H}$, et al. Cytokine-specific central monoamine alterations induced by interleukin-1, -2 and -6. Brain Res 1994; 643:40-49.

7. Oades RD, Dauvermann MR, Schimmelmann BG, Schwarz MJ, Myint AM. Attention-deficit hyperactivity disorder ( $A D H D$ ) and glial integrity: S100B, cytokines and kynurenine metabolism--effects of medication. Behav Brain Funct 2010;6:29.

8. Hunter CA, Jones SA. IL-6 as a keystone cytokine in health and disease. Nat Immunol 2015;16:448-457.

9. Erta M, Quintana A, Hidalgo J. Interleukin-6, a major cytokine in the central nervous system. Int J Biol Sci 2012;8:12541266.

10. Uzun G, Özdem S. Visfatin and its effects. J Turk Clin Biochem 2013;11:119-130. Turkish.

11. Wędrychowicz A, Zając A, Pilecki M, Kościelniak B, Tomasik PJ. Peptides from adipose tissue in mental disorders. World I Psychiatry 2014;4:103-111.

12. Darwish AH, Elgohary TM, Nosair NA. Serum interleukin-6 level in children with attention-deficit hyperactivity disorder (ADHD). J Child Neurol 2019;34:61-67.

13. Chang JP, Mondelli V, Satyanarayanan SK, Chiang YJ, Chen $\mathrm{HT}$, Su KP, et al. Cortisol, inflammatory biomarkers and neurotrophins in children and adolescents with attention deficit hyperactivity disorder (ADHD) in Taiwan. Brain Behav Immun 2020;88:105-113.

14. Xiang-Dong $\mathrm{P}$, Zhang L, Hong $C$, Jingjing $\mathrm{K}$, Jinping J. Correlation between interleukin-1 $\beta$, interleukin-6, tumor necrosis factor- $\alpha$ and attention deficit hyperactivity disorder. Matern Child Health Care China 2012;27:370-373.

15. Leffa DT, Bellaver B, de Oliveira C, de Macedo IC, de Freitas JS, Grevet EH, et al. Increased oxidative parameters and decreased cytokine levels in an animal model of attention-deficit/hyperactivity disorder. Neurochem Res 2017;42:3084-3092.

16. Ghaffari MA, Mousavinejad E, Riahi F, Mousavinejad M, Afsharmanesh MR. Increased serum levels of tumor necrosis factor-alpha, resistin, and visfatin in the children with autism spectrum disorders: a case-control study. Neurol Res Int
2016;2016:9060751.

17. Hedayati M, Hakami M, Hedayati M. Association between serum levels of visfatin and binge eating disorders in overweight women. Int I Rev Life Sci 2015;5:838-841.

18. Ziora K, Oświęcimska J, Swiętochowska E, Ziora D, Stojewska $\mathrm{M}$, Suwała A, et al. Assessment of serum visfatin levels in girls with anorexia nervosa. Clin Endocrinol (Oxf) 2012;76:514519.

19. Levin RL, Rawana JS. Attention-deficit/hyperactivity disorder and eating disorders across the lifespan: a systematic review of the literature. Clin Psychol Rev 2016;50:22-36.

20. Surman CB, Randall ET, Biederman J. Association between attention-deficit/hyperactivity disorder and bulimia nervosa: analysis of 4 case-control studies. J Clin Psychiatry 2006;67: 351-354.

21. Nazar BP, Bernardes C, Peachey G, Sergeant J, Mattos P, Treasure J. The risk of eating disorders comorbid with attention-deficit/hyperactivity disorder: a systematic review and meta-analysis. Int J Eat Disord 2016;49:1045-1057.

22. Gökler B, Ünal F, Pehlivantürk B, Kültür EÇ, Akdemir D, Taner $\mathrm{Y}$. [Reliability and validity of schedule for affective disorders and schizophrenia for school age children-present and lifetime version-Turkish version (K-SADS-PL-T)]. Turk J Child Adolesc Ment Health 2004;11:109-116. Turkish.

23. Mukaddes NM. [Yaşam Boyu Dikkat Eksikliği Hiperaktivite Bozukluğu ve Eşlik Eden Durumlar]. Istanbul:Nobel Tip;2015. Turkish.

24. Misener VL, Schachar R, Ickowicz A, Malone M, Roberts W, Tannock R, et al. Replication test for association of the IL-1 receptor antagonist gene, IL $1 R N$, with attention-deficit/hyperactivity disorder. Neuropsychobiology 2004;50:231-234.

25. Verlaet AAJ, Breynaert A, Ceulemans B, De Bruyne T, Fransen $\mathrm{E}$, Pieters $\mathrm{L}$, et al. Oxidative stress and immune aberrancies in attention-deficit/hyperactivity disorder (ADHD): a case-control comparison. Eur Child Adolesc Psychiatry 2019;28:719729 .

26. Donfrancesco R, Nativio P, Di Benedetto A, Villa MP, Andriola E, Melegari MG, et al. Anti-Yo antibodies in children with ADHD: first results about serum cytokines. J Atten Disord 2020;24:1497-1502.

27. Corominas-Roso M, Armario A, Palomar G, Corrales M, Carrasco J, Richarte V, et al. IL-6 and TNF- $\alpha$ in unmedicated adults with $A D H D$ : relationship to cortisol awakening response. Psychoneuroendocrinology 2017;79:67-73.

28. Baranowska-Bik A, Baranowska B, Martyńska L, Litwiniuk A, Kalisz M, Kochanowski J, et al. Adipokine profile in patients with anorexia nervosa. Endokrynol Pol 2017;68:422-429.

29. Dostálová I, Sedlácková D, Papezová H, Nedvídková J, Haluzík M. Serum visfatin levels in patients with anorexia nervosa and bulimia nervosa. Physiol Res 2009;58:903-907.

30. Oades RD, Myint AM, Dauvermann MR, Schimmelmann BG, Schwarz MJ. Attention-deficit hyperactivity disorder (ADHD) and glial integrity: an exploration of associations of cytokines 
and kynurenine metabolites with symptoms and attention. Behav Brain Funct 2010;6:32.

31. Genc S, Kusku-Kiraz Z, Dervisoglu E, Oztop N, Dinccag N, Gurdol F. The relation of oxidative stress biomarkers with proinflammatory cytokines in gestational diabetes. Clin Investig 2017;7:43-48.
32. Karakoç S, Şahin Calapoğlu N, Gonca T, Evgen Tülüceoğlu E, Öztürk Ö, Calapoğlu M. Relationship between adiponectin, interleukin-6 and tumour necrosis factor-alpha levels and body mass index change in obesity. Future Vis J 2019;3:1-8. Turkish. 